\title{
Deuterium Isotope Effect on the Dissociation of Weak Acids in Water and Deuterium Oxide
}

\author{
R. A. Robinson, ${ }^{1}$ Maya Paabo, and Roger G. Bates \\ Institute for Materials Research, National Bureau of Standards, Washington, D.C. 20234
}

(November 14, 1968)

\begin{abstract}
The dissociation constants of $o$-nitroanilinium ion, $m$-nitroanilinium ion, and 4-chloro-2,6-dinitrophenol in deuterium oxide at $25^{\circ} \mathrm{C}$ have been determined by a spectrophotometric method, and an emf method has been used to obtain $\left(p K_{1}+p K_{2}\right) / 2$ for citric acid in deuterium oxide. In addition, data for the dissociation constants of other weak acids in ordinary and heavy water have been critically examined with a view to clarifying the relationship between the deuterium isotope effect and the intrinsic strength of the acid. The difference $\Delta p K$ between the $p K$ value in deuterium oxide and that in water varies linearly with $p K$ above $p K=7$. Two stronger inorganic acids (sulfuric and phosphoric) also appear to lie on an extension of this same line. On the contrary, a considerable group of organic acids with $p K$ less than 7 have values of $\Delta p K$ that are more or less constant near $\Delta p K=0.55$. It appears, therefore, that the isotope effect is more complex than has heretofore been assumed.
\end{abstract}

Key words: Acidic dissociation; acidity; deuterium isotope effect; dissociation constants; heavy water; isotope effect; $p K$ values.

\section{Introduction}

Shortly after the discovery of heavy water by Urey, Brickwedde, and Murphy [1] ${ }^{2}$ in 1932 , it was shown by Lewis and Schutz [2] that acids are weaker in deuterium oxide than they are in ordinary water as solvent. For example, the dissociation constant of chloroacetic acid was found to be 2.7 times greater in ordinary water than in heavy water. From this study and the work of LaMer and his colleagues $[3,4,5]$ and of Martin and Butler [6], it appears that the difference in $p K$ value, $\Delta p K=p K\left(\right.$ in $\left.\mathrm{D}_{2} \mathrm{O}\right)-p K\left(\right.$ in $\mathrm{H}_{2} \mathrm{O}$ ), increases approximately linearly with an increase in $p K$ (in $\mathrm{H}_{2} \mathrm{O}$ ). This relation has been ascribed [7] to a difference in zero-point energy between the isotopes in the acid molecules or perhaps [8] to a difference in zero-point energy between the hydrogen-bonded molecules and the solvent. Thus, $\Delta p K=0.43$ for chloroacetic acid, 0.50 for benzoic acid [5], and 0.56 for $p$-nitrophenol [6]. Figure 1 is a plot of these $p K$ differences for 11 acids from measurements made prior to 1940 .

Curry and Hugus [9] have found $\Delta p K=0.60$ for the second stage of dissociation of carbonic acid, giving a point not far from the straight line drawn in figure 1 . This is true also for the data for 2,2,2-trifluoroethanol and 2-chloroethanol [10]. McDougall and Long [11] have determined the $p K$ differences for 13 acids'Present address: Department of Chemistry, State University of New York at Bingham-
ton, Binghamton, New York 13901 .

2 Figures in brackets indicate the literature references at the end of this paper. iodic, oxalic (both stages of dissociation), $\gamma$-resorcylic, phosphoric (first stage), chloroacetic, salicylic, $m$ nitrobenzoic, and glycolic acids and for 2,4- and 2,6-dinitrophenol and $o$ - and $p$-nitrophenol. A plot of their data gives points not far from the straight line in figure 1 .

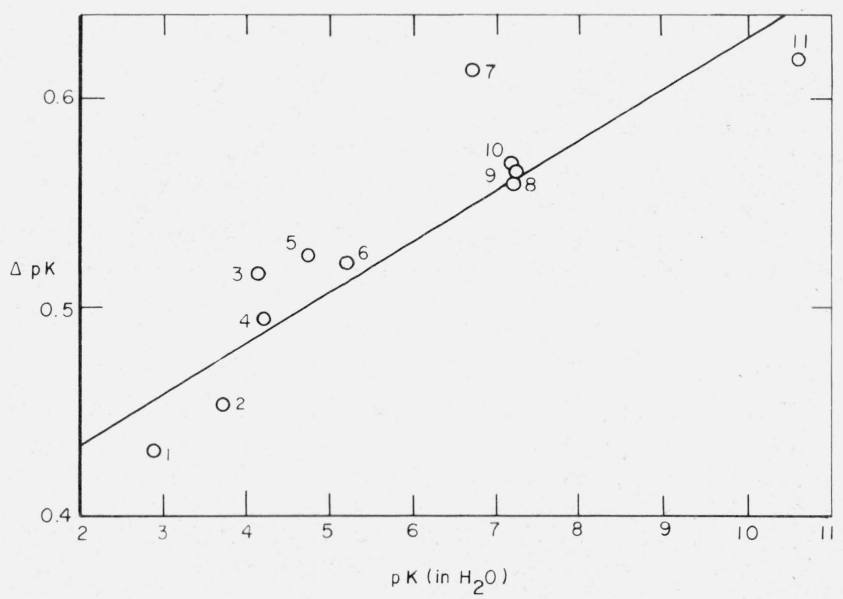

FigURE 1. Deuterium isotope effects $(\Delta \mathrm{pK})$ for weak acids obtained prior to 1940 , plotted as a function of the $\mathrm{pK}$ of the acid in $\mathrm{H}_{2} \mathrm{O}$.

1. Chloroacetic acid

2. 2,6-Dinitrophenol

3. 2,4-Dinitrophenol

Benzoic acid

5. Acenzoic acid

6. 2,5-Dinitrophenol
7. 3,5-Dinitrophenol

8. Dihydrogen phosphate ion

9. $p$-Nitrophenol

10. o-Nitrophenol

10. $o$-Nitrophenol
11. Hydroquinone. 
Other results, however, do not always support this relationship. For phosphoric acid, $p K_{1}=2.148$ (in $\mathrm{H}_{2} \mathrm{O}$ ), McDougall and Long found $\Delta p K=0.234$, in contrast to the value of $\Delta p K=0.438$ predicted from figure 1 . For salicylic acid, with $p K=2.996$ (in $\mathrm{H}_{2} \mathrm{O}$ ),$\Delta p K=0.75$, whereas $\Delta p K=0.46$ would be consistent with the plot in figure 1 ; this discrepancy may well be due to the abnormal amount of hydrogen bonding in salicylic acid. Although, more recently, Glasoe [12] has found $\Delta p K=0.56$ for salicylic acid, this is still higher than one would expect from figure 1 .

Furthermore, the isotope effect found by McDougall and Long [11] for $o$-nitrophenol $(\Delta p K=0.75)$ seems high: Martin and Butler [6] gave $\Delta p K=0.57$ and Glasoe [12] gave $\Delta p K=0.60$. On the contrary, the value for $p$-nitrophenol $\Delta p K=0.48$, seems somewhat low: Martin and Butler found $\Delta p K=0.56$ and Glasoe $\Delta p K=0.58$. The value $(\Delta p K=0.70)$ for 2,4 -dinitrophenol is higher than that of Martin and Butler $(\Delta p K=0.52)$ and of Glasoe $(\Delta p K=0.56)$; Bell and Kuhn [13] found $\Delta p K=0.52$.

The apparent effect of an unusual amount of hydrogen bonding is also noted [14] in maleic acid. It was found that $\Delta p K=0.625$ for the first stage in the dissociation of maleic acid. As the $p K$ value in ordinary water is 1.921 , one might expect, from figure 1 , that $\Delta p K$ would be about 0.43 . On the contrary, for the second stage in the dissociation of maleic acid $\Delta p K$ was found to be 0.379 ; with $p K_{2}=6.225$ in ordinary water, one might expect $\Delta p K=0.54$.

This abnormal hydrogen bonding is often associated with an unusually high value of the ratio of $K_{1} / K_{2}$ in ordinary water. For maleic acid, this ratio is $2 \times 10^{4}$. But a high value of this ratio does not always mean an abnormal value of $\Delta p K$. Thus, Glasoe [15] found for diethylmalonic acid $\left(p K_{1}=2.21, p K_{2}=7.33\right.$ in ordinary water, $K_{1} / K_{2}=1.32 \times 10^{5}$ ) that $\Delta p K=0.49$ for the first stage of dissociation and $\Delta p K=0.41$ for the second stage. Further anomalies are found in highly alkylated succinic acids [16]; thus, a difference of $\Delta p K=0.90$ is indicated for the first stage of dissociation of tetraethylsuccinic acid, the $p K$ value in ordinary water being 3.39. This is almost the highest value of $\Delta p K$ yet found.

Bell and Kuhn [13] have studied the isotope effect on the dissociation of 13 acids. The $p K$ values of these acids in ordinary water ranged from 2.50 to 5.20 and their values of $\Delta p K$, with one exception, lie within 0.05 of the straight line in figure 1 . The exception is bromoacetic acid. Their conclusion is that there is little to support a linear relation for the carboxylic acids, although a better case can be made for the phenols and alcohols.

In recent years, we have made a number of measurements of the $p K$ values of acids in deuterium oxide solution, and it seems worthwhile to examine the relation of our results to other work. While we do not claim to have a complete solution to the problem, we have come to the very tentative conclusion that the linear relation may be valid for acids with $p K$ greater than about 7 , but that $\Delta p K$ is more or less constant at about 0.55 for stronger acids. Two notable excep- tions, namely the first acid group of phosphoric acid and the second of sulfuric acid, will be discussed later in this paper.

\section{Experimental Procedures}

A commercial preparation of $o$-nitroaniline was recrystallized twice from methanol. $m$-Nitroaniline and 4-chloro-2,6-dinitrophenol were purified as described before [17]. A solution of deuterium chloride obtained commercially was standardized by gravimetric determination of chloride (weighing as silver chloride). The dissociation constants of the phenol and the two anilines were measured by a spectrophotometric method already described [18].

The potassium dihydrogen citrate was a portion of the same sample used in other work [19]. Emf measurements were made with cells containing potassium dideuteriocitrate and potassium chloride, using deuterium gas electrodes and silver-silver chloride electrodes; the cells were those used in the earlier work [19]. The dideuteriocitrate was formed in solution by exchange between potassium dihydrogen citrate and the deuterium oxide solvent.

\section{TABLE 1. The dissociation constant of o-nitroanilinium ion in deuterium oxide solution at $25^{\circ} \mathrm{C}$}

Conc. of $o$-Nitroaniline: $1.74 \times 10^{-4} M, 1 \mathrm{~cm}$ cell, $418 \mathrm{~nm}, D_{1}=0, D_{2}=0.776$.

\begin{tabular}{|c|c|c|c|c|}
\hline $\begin{array}{c}\text { Conc. of } \\
\text { DCl }^{\mathrm{a}}\end{array}$ & $D$ & $\log \frac{D_{2}-D}{D-D_{1}}$ & $-\log m_{\mathrm{D}^{+}}$ & $p K^{\prime}$ \\
\hline 0 & & & & ${ }^{b} 0.305$ \\
\hline 0.1552 & 0.580 & -0.471 & 0.809 & .338 \\
\hline .2983 & .455 & -.151 & .525 & .374 \\
\hline .4010 & .398 & -.022 & .397 & .375 \\
\hline .4536 & .366 & +.049 & .343 & .392 \\
\hline .5352 & .321 & +.151 & .271 & .422 \\
\hline .6447 & .280 & +.248 & .191 & .439 \\
\hline
\end{tabular}

${ }^{a}$ In moles per kilogram of solvent.

${ }^{b}$ Extrapolated by means of the equation $p K^{\prime}=0.305+0.204 m_{\mathrm{DCl}}$.

TABLE 2. The dissociation constant of $\mathrm{m}$-nitroanilinium ion in deuterium oxide solution at $25^{\circ} \mathrm{C}$

Conc. of $m$-Nitroaniline: $3.98 \times 10^{-4} M\left(3.61 \times 10^{-4} \mathrm{~mol} / \mathrm{kg}\right), 1 \mathrm{~cm}$ cell, $360 \mathrm{~nm}$, $D_{1}=0.038, D_{2}=0.568$.

\begin{tabular}{c|r|r|r|r}
\hline \hline $\begin{array}{c}\text { Conc. of } \\
\text { DCl }^{\mathrm{a}}\end{array}$ & \multicolumn{1}{|c|}{$D$} & $\log \frac{D_{2}-D}{D-D_{1}}$ & $-\log m_{\mathrm{D}+}$ & $p K$ \\
\hline & & & & \\
0.000801 & 0.362 & -0.197 & 3.180 & 2.983 \\
.000984 & .334 & -.102 & 3.083 & 2.981 \\
.001460 & .272 & +.102 & 2.900 & 3.002 \\
.001784 & .244 & +.197 & 2.806 & 3.003 \\
.002081 & .225 & +.263 & 2.733 & 2.996 \\
\hline
\end{tabular}

Average $p K$. .2 .993

a In moles per kilogram of solvent. 
TABLE 3. The dissociation constant of 4-chloro-2,6dinitrophenol in deuterium oxide solution at $25{ }^{\circ} \mathrm{C}$

Conc. of 4-Chloro-2,6-dinitrophenol: $8.06 \times 10^{-5} M\left(7.30 \times 10^{-5} \mathrm{~mol} / \mathrm{kg}\right), 1 \mathrm{~cm}$ cell, $447 \mathrm{~nm}$, $D_{1}=0.002, D_{2}=0.583$.

\begin{tabular}{c|r|r|r|r|r}
\hline \hline $\begin{array}{c}\text { Conc. of } \\
\text { DCl }^{\text {a }}\end{array}$ & \multicolumn{1}{|c|}{$D$} & $\log \frac{D_{2}-D}{D-D_{1}}$ & $-\log m_{\mathrm{D}+}$ & $-2 \log \gamma^{\mathrm{b}}$ & $p K$ \\
\hline & & & & \\
\hline .0002153 & 0.341 & -0.146 & 3.589 & 0.017 & 3.460 \\
.0002587 & .317 & -.073 & 3.525 & .018 & 3.470 \\
.0002807 & .311 & -.055 & 3.495 & .019 & 3.459 \\
.0004352 & .248 & +.134 & 3.331 & .023 & 3.488 \\
.0004617 & .239 & +.162 & 3.308 & .023 & 3.493 \\
.0005448 & .217 & +.231 & 3.243 & .025 & 3.499 \\
.0008741 & .160 & +.428 & 3.049 & .031 & 3.508 \\
\hline
\end{tabular}

Average $p K$

3.482

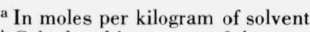

${ }^{\mathrm{b}}$ Calculated by means of the equation

$$
-2 \log \gamma=\frac{1.0826 I^{1 / 2}}{1+1.5 I^{1 / 2}} .
$$

\section{Results}

\subsection{Results of Present Work}

The spectrophotometric data for the two anilines and the phenol are given in tables 1,2 , and 3 . The notation is the same as that used previously [18]. For the case of the anilines, the $p K$ values quoted are those corresponding to the acidic dissociation of the anilinium ion,

$$
\mathrm{BH}^{+} \leftrightharpoons \mathrm{H}^{+}+\mathrm{B}
$$

All values are expressed on the molality scale. The results are collected in table 4 and compared with the $p K$ values found previously in ordinary water as solvent.

The $p K$ values of $o$-nitroaniline and $m$-nitroaniline given by Högfeldt and Bigeleisen [21] are not in good agreement with the present data. Nevertheless, the differences of $p K(\Delta p K=0.61$ for $o$-nitroaniline and 0.56 for $m$-nitroaniline) are in moderate agreement with those found in the present work. These $p K$ differences give points lying considerably above the straight line in figure 1.

Bell and Kuhn [13] give $p K$ (in $\left.\mathrm{H}_{2} \mathrm{O}\right)=2.96$, $\Delta p K=0.49$, for 4-chloro-2,6-dinitrophenol, so that $p K\left(\right.$ in $\left.\mathrm{D}_{2} \mathrm{O}\right)=3.45$. However, Bell and Kuhn based all

TABle 4. Dissociation constants in aqueous and deuterium oxide solutions at $25{ }^{\circ} \mathrm{C}$ determined by the spectrophotometric method

\begin{tabular}{l|r|r|r}
\hline \hline & $p K\left(\right.$ in $\left.\mathrm{H}_{2} \mathrm{O}\right)$ & $p K\left(\right.$ in $\left.\mathrm{D}_{2} \mathrm{O}\right)$ & \multicolumn{1}{c}{$\Delta p K$} \\
\hline & & & \\
\hline -Nitroanilinium ion............ & $-0.263[20]$ & 0.305 & 0.568 \\
-Nitroanilinium ion......... & $2.460[17]$ & 2.993 & .533 \\
4-Chloro-2,6-dinitrophenol.... & $2.969[17]$ & 3.482 & .513 \\
\hline
\end{tabular}

their data for deuterium oxide solutions on $p K=5.28$ for acetic acid. We now know [22] that $p K=5.313$ for acetic acid in deuterium oxide (molal scale) or $p K=5.270$ (molar scale), so it is evident that their values all relate to the molar scale. Their value for 4-chloro-2,6-dinitrophenol on the molal scale is, therefore, 3.49 , in agreement with the value found in the present work.

Table 5 gives values of the emf of the cell

$$
\mathrm{Pt} ; \mathrm{D}_{2}(\mathrm{~g}, 1 \mathrm{~atm}), \mathrm{KD}_{2} \mathrm{Cit}(m), \mathrm{KCl}(m=0.01), \mathrm{AgCl} ; \mathrm{Ag}
$$

at $25{ }^{\circ} \mathrm{C}$ for four molalities of the citrate salt. The emf of this cell, $E$, is related to the $p\left(a_{\mathrm{D}} \gamma_{\mathrm{Cl}}\right)(\equiv-\log$ $\left.m_{\mathrm{D}^{+}} \cdot \gamma_{\mathrm{D}^{+}} \cdot \gamma_{\mathrm{Cl}^{-}}\right)$value of the buffer solution by the equation

$$
\frac{E-E^{\circ}}{k}+\log m_{\mathrm{KCl}}=p\left(a_{\mathrm{D}} \gamma_{\mathrm{Cl}}\right)
$$

where $m_{\mathrm{KCl}}=0.01 \mathrm{~mol} \mathrm{~kg}{ }^{-1}, k=(R T \ln 10) / \mathrm{F}$, and $E^{\circ}$, the standard potential of the silver-silver chloride electrode, is taken to be $0.21266 \mathrm{~V}$ at $25{ }^{\circ} \mathrm{C}$ [23].

With the aid of the following convention [24],

$$
-\log \gamma_{\mathrm{Cl}^{-}}=\frac{A \sqrt{I}}{1+1.5 \sqrt{I}}
$$

values of $\log \gamma_{\mathrm{Cl}^{-}}$can be calculated and are given in the fourth row of table 5 . As will be shown in the appendix at the end of this paper, $p\left(a_{\mathrm{D}} \gamma_{\mathrm{Cl}}\right)-\log \gamma_{\mathrm{Cl}}-$ (values of which are given in the fifth row) is a first approximation to $\left(p K_{1}+p K_{2}\right) / 2$. A good value of this quantity is obtained by extrapolation to $I=0$, whereupon $\left(p K_{1}+p K_{2}\right) / 2$ is found to be 4.483. A more detailed analysis, taking into account the effect of overlapping stages of dissociation, is also given in the appendix and leads to values of $\left(p K_{1}+p K_{2}\right) / 2=4.468$,

\begin{tabular}{|c|c|c|c|c|}
\hline$m$ & 0.02 & 0.06 & 0.08 & 0.10 \\
\hline$E(\mathrm{~V}) \ldots \ldots \ldots$ & 0.59167 & 0.58975 & 0.58913 & 0.58863 \\
\hline$p\left(a_{\mathrm{D}} \gamma_{\mathrm{Cl}}\right) \ldots \ldots \ldots \ldots$ & $4.406_{7}$ & $4.374_{3}$ & $4.363_{8}$ & $4.355_{4}$ \\
\hline$-\log \gamma_{\mathrm{Cl}}-\ldots \ldots \ldots \ldots \ldots$ & 0.0744 & 0.1025 & 0.1120 & 0.1199 \\
\hline$p\left(a_{\mathrm{D}} \gamma_{\mathrm{Cl}}\right)-\log \gamma_{\mathrm{Cl}}-\ldots \ldots$ & 4.481 & 4.477 & 4.476 & 4.475 \\
\hline$\left(p K_{1}+p K_{2}\right) / 2 \ldots \ldots \ldots \ldots$ & 4.468 & 4.467 & 4.470 & 4.469 \\
\hline
\end{tabular}
$\Delta p K=0.523$.

TABLE 5. Emf measurements of cells containing potassium dideuteriocitrate at $25^{\circ} \mathrm{C}$

$\mathrm{Pt} ; \mathrm{D}_{2}, \mathrm{KD}_{2} \mathrm{Cit}(m), \mathrm{KCl}(m=0.01), \mathrm{AgCl} ; \mathrm{Ag}$

\subsection{Results Derived From Earlier Work at NBS}

Some additional values of $\Delta p K$ can be derived from emf measurements of cells without transference. These are summarized in table 6 . All of the $p K$ values are on the molal scale.

In addition, the $p K$ values of a few acids in deuterium oxide can be derived from emf measurements which 
TABLE 6. Dissociation constants from emf measurements in aqueous and deuterium oxide solutions at $25^{\circ} \mathrm{C}$

\begin{tabular}{|c|c|c|c|}
\hline & $p K\left(\right.$ in $\left.\mathrm{H}_{2} \mathrm{O}\right)$ & $p K\left(\right.$ in $\left.\mathrm{D}_{2} \mathrm{O}\right)$ & $\Delta p K$ \\
\hline Acetic acid......... & $4.756[25]$ & $5.313[22]$ & 0.557 \\
\hline Deuterioacetic acid........ & $4.771[26]$ & $5.325[27]$ & .554 \\
\hline $\begin{array}{l}\text { Phosphoric acid (second } \\
\text { step). }\end{array}$ & $7.201[28]$ & $7.780[29]$ & .579 \\
\hline Self-dissociation of solvent & $13.997[30]$ & $14.955[31]$ & .958 \\
\hline
\end{tabular}

were made for a different purpose [32]. For example, the emf of the cell

$\mathrm{Pt} ; \mathrm{D}_{2}, \mathrm{NaDCO}_{3}(0.025 \mathrm{~m}), \mathrm{Na}_{2} \mathrm{CO}_{3}(0.025 \mathrm{~m})$,

\section{$\mathrm{NaCl}(0.025 \mathrm{~m}), \mathrm{AgCl} ; \mathrm{Ag}$}

was found to be $0.94815 \mathrm{~V}$ at $25{ }^{\circ} \mathrm{C}$ and, therefore, $-\log \left(a_{\mathrm{D}^{+}} \gamma_{\mathrm{Cl}^{-}}\right)$, designated $p\left(a_{\mathrm{D}} \gamma_{\mathrm{Cl}}\right)$, is 10.831. The dissociation constant is given by the expression

$$
p K=p\left(a_{\mathrm{D}} \gamma_{\mathrm{Cl}}\right)-\log \frac{m_{\mathrm{CO}_{3}^{--}}}{m_{\mathrm{DCO}_{3}^{-}}}-\log \frac{\gamma_{\mathrm{CO}_{3}^{--}}}{\gamma_{\mathrm{DCO}_{3}^{-}}}
$$

where this $p K$ refers to the second stage of dissociation of carbonic acid in deuterium oxide. For this acid in ordinary water, Harned and Scholes [33] found that the equation

$$
-\log \frac{\gamma_{\mathrm{CO}_{3}^{-}}}{\dot{\gamma}_{\mathrm{HCO}_{3}^{-}} \gamma_{\mathrm{Cl}^{-}}}=\frac{2 \mathrm{AII}^{1 / 2}}{1+1.414 I^{1 / 2}}
$$

gave a good representation of the activity coefficient term in eq (3). Thus, for a cell in which all three solutes were present at a concentration of $0.02620 \mathrm{~m},-\log$ $\left(a_{\mathrm{H}}^{+} \cdot \gamma_{\mathrm{Cl}^{-}}\right) \quad\left[\right.$ designated $\left.p\left(a_{\mathrm{H}} \gamma_{\mathrm{Cl}}\right)\right]=10.096,2 A I^{1 / 2}$ $/\left(1+1.414 I^{1 / 2}\right)=0.245$, and the apparent $p K$ value is 10.340 ; this requires only a small correction of -0.011 , an allowance for the inadequacy of eq (4) and the necessity of a small, additional term linear in $I$, to give the true value, $p K=10.329$. Assuming that eq (4), together with this small correction, is valid for solutions in deuterium oxide, and making the appropriate changes in the numerical value of the $A$ parameter in eq (4) to allow for the different dielectric constant and density of heavy water, we calculate $-\log \gamma_{\mathrm{CO}_{3}^{-}}-/\left(\gamma_{\mathrm{DCO}_{3}^{-}} \gamma_{\mathrm{Cl}^{-}}\right)$ $=0.250$ and $p K=11.070$ in deuterium oxide; $\Delta p K$ $=0.741$.

The $p K$ for the second dissociation of deuteriocarbonic acid in heavy water has recently been determined carefully in this laboratory [34]. The value obtained $\left(11.076\right.$ at $25^{\circ} \mathrm{C}$ ) lends confidence to the procedure described above, which provided a value of $p K=11.070$ from a single measurement of $p\left(a_{\mathrm{D}} \gamma_{\mathrm{Cl}}\right)$.

Similarly, the emf of the cell

Pt; $\mathrm{D}_{2}, \mathrm{Na}_{2} \mathrm{~B}_{4} \mathrm{O}_{7}(0.05 m), \mathrm{NaCl}(0.05 \mathrm{~m}), \mathrm{AgCl} ; \mathrm{Ag}$ is $0.87378 \mathrm{~V}$ at $25^{\circ} \mathrm{C}$ and, hence, $p\left(a_{\mathrm{D}} \gamma_{\mathrm{Cl}}\right)=9.875$. The $p K$ value of boric acid in deuterium oxide is given by the equation

$$
p K=p\left(a_{\mathrm{D}} \gamma_{\mathrm{Cl}}\right)-\log \frac{m_{\mathrm{BO}_{2}-}}{m_{\mathrm{DBO}_{2}}}-\log \frac{\gamma_{\mathrm{BO}_{2}-}}{\gamma_{\mathrm{DBO}_{2}} \cdot \gamma_{\mathrm{Cl}}} .
$$

In their investigation of this acid in ordinary water, Manov, DeLollis, and Acree [35] found that the corresponding equation for aqueous solutions -could be written

$$
p K=p\left(a_{\mathrm{H}} \gamma_{\mathrm{Cl}}\right)-\log \frac{m_{\mathrm{BO}_{2}^{-}}}{m_{\mathrm{HBO}_{2}}}-\beta I
$$

with $\beta=0.07 \mathrm{~mol}^{-1} \mathrm{~kg}$. Assuming that the same value of $\beta$ can be used for deuterium oxide solutions, the $p K$ value of boric acid in deuterium oxide is found to be 9.864 , from which $\Delta p K=0.630$.

For phosphoric acid, a solution containing $\mathrm{D}_{3} \mathrm{PO}_{4}$ $\left(m_{1}=0.06544\right), \quad \mathrm{KD}_{2} \mathrm{PO}_{4} \quad\left(m_{2}=0.01579\right), \quad \mathrm{KCl}$ $\left(m_{3}=0.06544\right), I=0.1$, it was found [32] that $p\left(a_{\mathrm{D}} \gamma_{\mathrm{Cl}}\right)=2.107$. The equation for the first dissociation constant is

$$
\begin{aligned}
p K_{1} & =p a_{\mathrm{D}}-\log \frac{m_{\mathrm{D}_{2} \mathrm{PO}_{4}^{-}}}{m_{\mathrm{D}_{3} \mathrm{PO}_{4}}}-\log \frac{\gamma_{\mathrm{D}_{2} \mathrm{PO}_{4}^{-}}}{\gamma_{\mathrm{D}_{3} \mathrm{PO}_{4}}} \\
& =p a_{\mathrm{D}}-\log \frac{m_{2}+m_{\mathrm{D}^{+}}}{m_{1}-m_{\mathrm{D}^{+}}}-\log \frac{\gamma_{\mathrm{D}_{2} \mathrm{PO}_{4}^{-}}}{\gamma_{\mathrm{D}_{3} \mathrm{PO}_{4}}} .
\end{aligned}
$$

In calculating $p a_{\mathrm{D}}$ from $p\left(a_{\mathrm{D}} \gamma_{\mathrm{Cl}}\right)$, Covington, Paabo, Robinson, and Bates [32] calculated the activity coefficient of the chloride ion by means of the BatesGuggenheim convention [24], eq (2). If we assume that $-\log \gamma_{\mathrm{D}^{+}}=-\log \gamma_{\mathrm{Cl}^{-}}=0.114$, then $-\log m_{\mathrm{D}^{+}}=1.879$, $m_{\mathrm{D}^{+}}=0.01321$, and also assume that $-\log \gamma_{\mathrm{D}_{2} \mathrm{PO}_{\overline{4}}}$ ) $\gamma_{\mathrm{D}_{3} \mathrm{PO}_{4}}=0.114$, then, by eq (7), $p K_{1}=2.362$. The result is, however, very sensitive to the assumption made about the activity coefficient terms; if we assume the validity of the limiting Debye-Hückel equation,

$$
-\log \gamma=A I^{1 / 2}
$$

then $-\log \gamma=0.171, p a_{\mathrm{D}}=1.936,-\log m_{\mathrm{D}^{+}}=1.765$, $m_{\mathrm{D}^{+}}=0.01718$, and $p K_{1}=2.273$. On the contrary, if we assume the equation,

$$
-\log \gamma=\frac{A I^{1 / 2}}{1+7 B I^{1 / 2}}
$$

then $-\log \gamma=0.100, p a_{\mathrm{D}}=2.007,-\log m_{\mathrm{D}}{ }^{+}=1.907$, $m_{\mathrm{D}^{+}}=0.01239$, and $p K_{1}=2.382$. As $p K_{1}=2.148$ in ordinary water [36], $\Delta p K=0.214,0.125$, or 0.234 , depending on which of these assumptions about the activity coefficient terms is chosen.

Alternatively, $p K_{1}$ can be expressed in terms of $p\left(a_{\mathrm{D}} \gamma_{\mathrm{Cl}}\right)$ as follows:

$$
p K_{1} \approx p\left(a_{\mathrm{D}} \gamma_{\mathrm{Cl}}\right)-\log \frac{m_{2}+m_{\mathrm{D}^{+}}}{m_{1}-m_{\mathrm{D}^{+}}}
$$

with the plausible assumption that $\gamma_{\mathrm{D}_{2} \mathrm{PO}_{4}^{-}} /\left(\gamma_{\mathrm{D}_{3} \mathrm{PO}_{4}} \gamma_{\mathrm{Cl}^{-}}\right)$ 
is close to unity in these dilute buffer solutions. Unfortunately, this procedure does not remove the major source of uncertainty, namely the estimation of $m_{\mathrm{D}^{+}}$ needed to calculate the concentration term in eq (7). The same value of $p K_{1}$ is obtained from the two equations when $\log \gamma$ and $m_{\mathrm{D}^{+}}$are estimated in the same way.

Data are available for succinate buffer solutions, but the evaluation of the dissociation constants is complicated by the correction which has to be made for the deuterium ion concentration and the overlapping of the dissociation constants. Detailed consideration is reserved for the appendix at the end of this paper where it is shown that $\Delta p K=0.546$ for the first stage of dissociation of succinic acid and $\Delta p K=0.533$ for the second stage.

\section{Discussion}

\subsection{Isotope Effects Calculated From Data Obtained at NBS}

Figure 2 is a plot of $\Delta p K$ against $p K$ (in $\mathrm{H}_{2} \mathrm{O}$ ) for all the systems we have studied. The figure suggests an approximately linear variation of $\Delta p K$ with $p K$ for values of $p K$ greater than about 7 . For stronger acids, with a single exception, $\Delta p K$ seems to be approximately constant at about 0.55 , or even to pass through a flat minimum and then to increase slowly with decreasing $p K$ value.

The single exception we have found relates to the first stage of dissociation of phosphoric acid. Another exception (the second stage of sulfuric acid) will be discussed in the next section. The point shown in figure 2 for phosphoric acid is at $\Delta p K=0.214$. It was derived on the assumption of the Bates-Guggenheim convention not only for the activity coefficient of the chloride ion but also for the other ions taking part in the dissociation equilibrium. We have seen that the value of $\Delta p K$ for acids as strong as phosphoric $\left(K_{1}\right)$ and sulfuric $\left(K_{2}\right)$ is very sensitive to the assumption made about the value of this activity coefficient, but no reasonable assumption can raise $\Delta p K$ to a value consistent with the upper curve of figure 2 .

\subsection{Isotope Effects Calculated From Data Obtained in Other Laboratories}

The $p K$ value for 3,5-dinitrophenol in ordinary water has been found [37] to be 6.692 at $25^{\circ} \mathrm{C}$. Martin and Butler [6] found that $\Delta p K$ for this phenol, when plotted on a graph such as that shown in figure 1, gives a point lying above the straight line shown in this figure. This value has been confirmed recently [38] when $p K=7.305$ and $\Delta p K=0.613$ were derived from spectrophotometric measurements in deuterium oxide buffer solutions containing potassium dideuteriophosphate and disodium deuteriophosphate, the $p\left(a_{\mathrm{D}} \gamma_{\mathrm{Cl}}\right)$ values of which are known [29]. The point corresponding to this $\Delta p K$ value is plotted in figure 2 . It can be seen that it lies about 0.03 above the curve

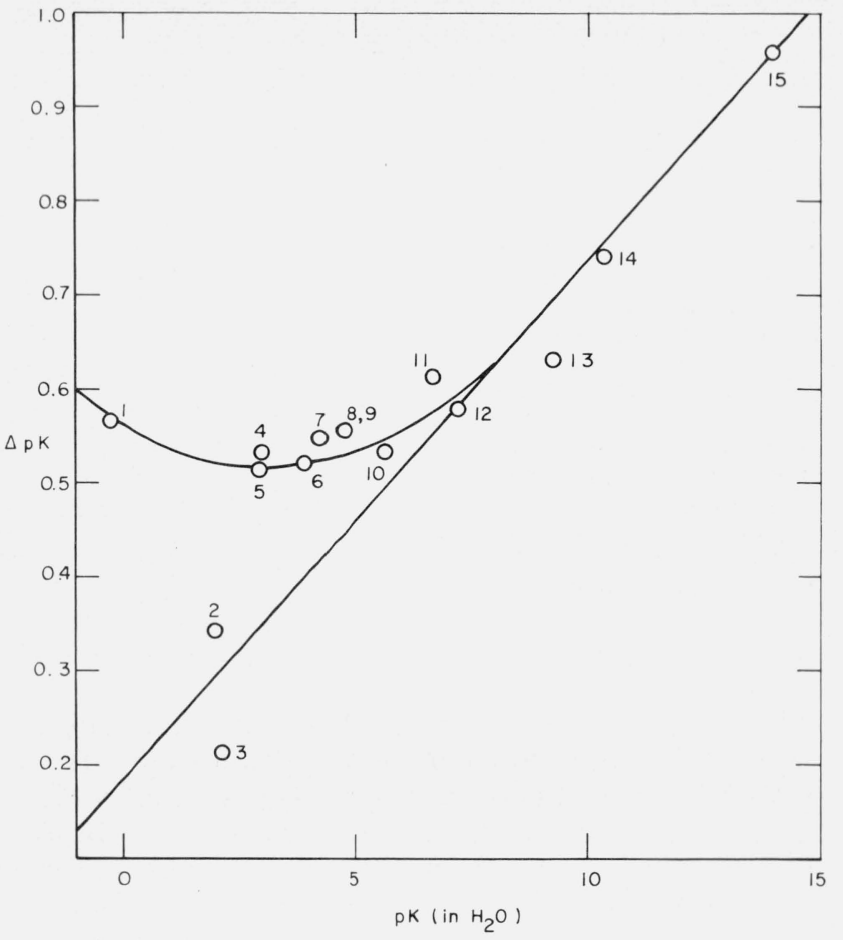

FIGURE 2. Deuterium isotope effects $(\Delta \mathrm{pK})$ for weak acids at $25{ }^{\circ} \mathrm{C}$, critically evaluated.

$\begin{array}{ll}\text { 1. } o \text {-Nitroanilinium ion } & 9 \text {. Deuterioacetic acid } \\ \text { 2. Bisulfate ion } & \text { 10. Hydrogen succinate ion } \\ \text { 3. Phosphoric acid (first step) } & \text { 11. 3,5-Dinitrophenol } \\ \text { 4. } m \text {-Nitroanilinium ion } & \text { 12. Dihydrogen phosphate ion } \\ \text { 5. 4-Chloro-2,6-dinitrophenol } & \text { 13. Boric acid } \\ \text { 6. Citric acid }\left[\left(p K_{1}+p K_{2}^{*}\right) / 2\right] & \text { 14. Bicarbonate ion } \\ \text { 7. Succinic acid (first step) } & \text { 15. Self-dissociation of solvent. }\end{array}$

7. Succinic acid (first step)

8. Acetic acid

drawn in the figure; it departs even further from the straight line drawn in this figure.

Lietzke and Stoughton [39] have studied the second stage of dissociation of deuteriosulfuric acid and derived a value of $p K_{2}=2.326$ at $25{ }^{\circ} \mathrm{C}$ from measurements of the solubility of silver sulfate in deuteriosulfuric acid. Spectrophotometric measurements [40] have given $p K_{2}=1.983$ for the second stage of dissociation of sulfuric acid in ordinary water, and hence $\Delta p K=0.343$. This value gives a point which is included in figure 2 and which undoubtedly belongs to the lower curve.

We now have measurements on 15 acids (only 14 points are shown in figure 2 , because those for acetic acid and deuterioacetic acid are almost coincident). All of these determinations depend on sound thermodynamic theory. A well-established solubility method was utilized for one acid, and highly accurate emf measurements of cells without liquid junction gave results for 10 other acids; the data for four acids were obtained by spectrophotometric measurements. For three of these the acidity of the medium was determined by the addition of known amounts of deuterium chloride, while the fourth depended on $p\left(a_{\mathrm{D}} \gamma_{\mathrm{Cl}}\right)$ values calculated from the emf of cells without liquid junction. The results are collected in table 7 . 
TABLE 7. Values of $\Delta \mathrm{pK}$ at $25^{\circ} \mathrm{C}$

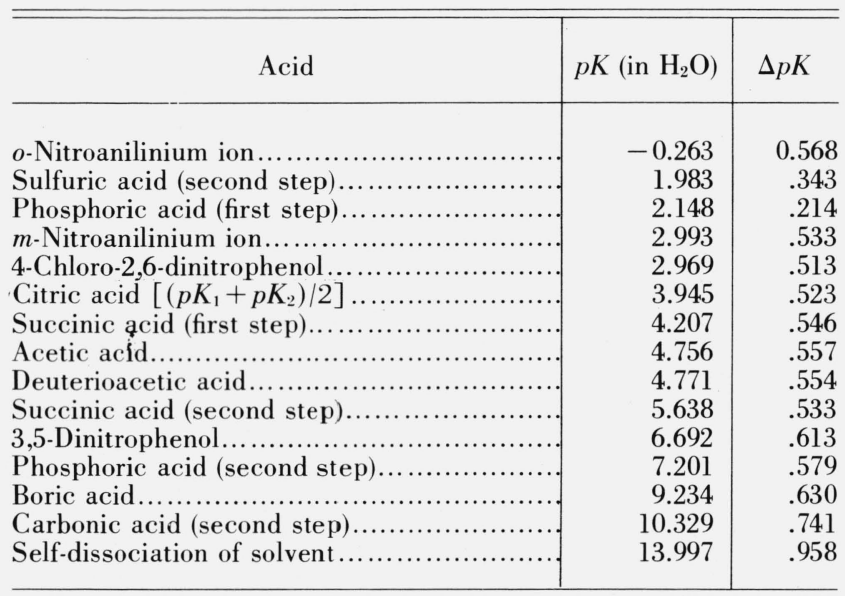

From the results given in table 7 and illustrated in figure 2 , it therefore seems evident that there are two distinct isotope effects. The only common factor which appears to separate the two effects seems to be that all "organic" acids give points on the upper curve, whereas the two acids which give points on the lower curve are "inorganic" or "mineral" acids. This unexpected conclusion must be regarded as a tentative one, since we have only two examples of the latter category, and we must await further work to confirm or deny its validity.

As both curves merge into one at $p K$ values greater than about 7 , it is the behavior of acids of lower $p K$ which is of most interest. Nevertheless, some recent measurements of acids of high $p K$ are of interest. Wehry and Rogers [41] have studied phenol and a number of substituted phenols in both ordinary water and in heavy water. For phenol itself $(p K=10.00$ in $\mathrm{H}_{2} \mathrm{O}$ ), they find $\Delta p K=0.62$ on the molarity scale, and therefore $\Delta p K=0.66$ on the molality scale. This is consistent with the curve in figure 2. Similarly, they find $\Delta p K=0.59$, again on the molality scale, for the 4-phenolsulphonate ion with $p K\left(\right.$ in $\left.\mathrm{H}_{2} \mathrm{O}\right)=8.97$, which is also consistent with the curve in figure 2. Furthermore, Wehry and Rogers give data for $p$-nitrophenol, $o$-bromophenol, $m$-methoxyphenol, 2-naphthol, and 4-hydroxyphenyltrimethylammonium chloride, all of which are consistent with this curve. Of more interest for our present purpose are their findings for two acids of lower $p K$ value. For 2,4-dinitrophenol $[p K$ (in $\left.\left.\mathrm{H}_{2} \mathrm{O}\right)=4.06\right], \Delta p K$ (molality scale) $=0.53$; and for 2,5-dinitrophenol [ $p K\left(\right.$ in $\left.\left.\mathrm{H}_{2} \mathrm{O}\right)=5.19\right], \Delta p K$ (molality scale) $=0.55$. Both these values of $\Delta p K$ clearly lie on the upper curve and not on the lower curve of figure 2.

Pentz and Thornton [42] find $\Delta p K=0.57,0.62$, and 0.54 for 2,4-dinitrophenol, $o$-nitrophenol, and the imidazolinium ion, respectively, all based on the molality scale. Their value for $o$-nitrophenol certainly does not fall on the lower curve of figure 2 and seems somewhat higher than one would expect for the upper curve. However, Martin and Butler [6] found $\Delta p K=0.61$ and Glasoe [12] $\Delta p K=0.64$, both values converted to the molality scale; there are thus three values for $o$-nitrophenol which suggest that the $\Delta p K$ value for this phenol is about 0.05 higher than the point read for the upper curve of figure 2 .

We have already mentioned that Bell and Kuhn [13] obtained a value of $\Delta p K=0.49$ on the molarity scale ( 0.53 on the molality scale) for 4-chloro-2,6-dinitrophenol, which compares well with our value of 0.513 (table 4). Neither value falls on the lower curve of figure 2. It is very useful to have this confirmation of the $\Delta p K$ value for an acid of this charge type with such a low $p K$ value, because it disposes of the argument that the part of the upper curve for $p K<3$ is peculiar to acids of the anilinium ion type. We now have a substituted phenol whose $\Delta p K$ value lies on the same curve. Bell and Kuhn obtained data for 12 other acids. Their $\Delta p K$ value for 2,4-dinitrophenol, $p K\left(\right.$ in $\left.\mathrm{H}_{2} \mathrm{O}\right)=4.07$, is 0.56 (molality scale). In agreement with the findings of Pentz and Thornton [42] $(\Delta p K=0.57)$ and of Wehry and Rogers [41] $(\Delta p K=0.53)$, this gives a point on the upper curve of figure 2 .

For 2,5-dinitrophenol, $p K$ (in $\mathrm{H}_{2} \mathrm{O}$ ) $=5.20$, Bell and Kuhn give $\Delta p K=0.57$ (molality scale), in agreement with $\Delta p K=0.55$ given by Wehry and Rogers and consistent with the upper curve of figure 2 . Bell and Kuhn give $\Delta p K=0.53$ (molality scale) for 2,6-dinitrophenol, $p K\left(\right.$ in $\left.\mathrm{H}_{2} \mathrm{O}\right)=3.73$; this gives a useful point in figure 2 because it relates to an acid of comparatively low $p K$, and the point lies exactly on the upper curve. They also found $\Delta p K$ values for 9 substituted acetic acids; the values of $p K$ (in $\mathrm{H}_{2} \mathrm{O}$ ) ranged from 2.50 to 5.03 and $\Delta p K$ from 0.45 to 0.58 .

Högfeldt and Bigeleisen [21] measured $\Delta p K$ for 8 acids of the anilinium ion charge type with $p K$ (in $\mathrm{H}_{2} \mathrm{O}$ ) ranging from -1.05 (4-chloro-2-nitroanilinium ion) to 2.76 (the protonated form of aminoazobenzene), and $\Delta p K$ (presumably on the molarity scale) ranged from 0.61 for the $o$-nitroanilinium ion to 0.50 for the 2,6dichloroanilinium ion. Again, these $\Delta p K$ values do not fall on the lower curve of figure 2 .

Benzoic acid is important because it is the archetype of many organic acids. Rule and La Mer [5] found $K$ (in $\mathrm{H}_{2} \mathrm{O}$ ) $/ K$ (in $\mathrm{D}_{2} \mathrm{O}$ ) $=3.13$ for this acid. They found $p K\left(\right.$ in $\left.\mathrm{D}_{2} \mathrm{O}\right)=7.749$ for the second stage of dissociation of phosphoric acid; a value of $p K=7.780$ on the molality scale has been measured recently [29], and it would seem therefore that Rule and La Mer were using either the "aquamolality" or the molarity scale. The correction to the molality scale is the same in either case, and hence Rule and La Mer's result for benzoic acid corresponds to $\Delta p K=0.54$ on the molality scale, again consistent with the upper but not the lower curve of figure 2 .

\subsection{Influence of Temperature on the Isotope Effect}

Most of the measurements referred to have been made at $25{ }^{\circ} \mathrm{C}$. It is known $[30,43]$ however, that the dissociation constants of many acids increase with an increase in temperature, pass through a maximum, and then decrease in value at higher temperatures. The $p K$ 
value of an acid can often [30] be represented by the equation

$$
p K=\frac{A_{1}}{T}-A_{2}+A_{3} T
$$

in which event the temperature corresponding to the maximum value of $K$ (or minimum value of $p K$ ) is

$$
T_{\max }=\left(A_{1} / A_{3}\right)^{1 / 2}
$$

and the $p K$ value at this temperature is given by the equation

$$
p K_{\min }=2\left(A_{1} A_{3}\right)^{1 / 2}-A_{2}
$$

It might well be argued that a comparison between $p K$ values in ordinary water and in deuterium oxide should be made, not at the same temperature, but at the temperature of minimum $p K$ value in each solvent. There are, unfortunately, few measurements over a temperature range by means of which this suggestion can be verified. Nevertheless, from measurements of the dissociation constants of acetic acid [22, 25] and deuterioacetic acid [26, 27] and that of the second stage of phosphoric acid [28, 29] in ordinary water and in deuterium oxide, as well as the "self-dissociation" constants of these two solvents $[30,31]$, we can derive the data in table 8 .

TABLE 8. Values of $\mathrm{pK}$ in ordinary water and in

\begin{tabular}{|c|c|c|c|c|c|}
\hline & \multicolumn{2}{|c|}{ Water } & \multicolumn{3}{|c|}{ Deuterium oxide } \\
\hline & $t_{\min }$ & $p K_{\min }$ & $t_{\min }$ & $p K_{\min }$ & $\Delta p K_{\min }$ \\
\hline Acetic acid............. & 22.4 & 4.756 & 32.0 & 5.310 & 0.554 \\
\hline Deuterioacetic acid... & 22.9 & 4.771 & 32.4 & 5.323 & 0.552 \\
\hline $\begin{array}{l}\text { Phosphoric acid (2nd } \\
\text { step)......................... }\end{array}$ & 42.7 & 7.180 & 47.7 & 7.744 & 0.564 \\
\hline $\begin{array}{l}\text { "Self-dissociation" } \\
\text { constant..................... }\end{array}$ & 239 & 11.382 & 221 & 12.356 & 0.974 \\
\hline
\end{tabular}
heavy water at the temperature of the minimum $\mathrm{pK}$ value

The temperature of maximum $K$ value (or minimum $p K$ value) is expressed in degrees Celsius. All $p K$ values are on the molality scale.

The $\Delta p K_{\min }$ value for the "self-dissociation" of the solvent obviously is not the same as those of the other three dissociation processes. It should be remembered, however, that the value for the "self-dissociation" of ordinary water at $239^{\circ} \mathrm{C}\left(p K_{\min }=11.382\right)$ was obtained by means of an equation fitted to experimental data covering the temperature range 0 to $60{ }^{\circ} \mathrm{C}$, the $p K$ value at $60{ }^{\circ} \mathrm{C}$ being 13.017. Similarly, the value for deuterium oxide $\left(p K_{\min }=12.356\right.$ at $\left.221{ }^{\circ} \mathrm{C}\right)$ was obtained by an extrapolation of experimental data covering the temperature range 5 to $50{ }^{\circ} \mathrm{C}$, the $p K$ value at $50^{\circ} \mathrm{C}$ being 14.182 .
Extrapolation to temperatures so far from the experimental range cannot give more than a qualitative value of $t_{\min }$ and $p K_{\min }$, and more has never been claimed. The value of $\Delta p K_{\min }$ in table 8 , therefore, contributes little to any quantitative theory that may be developed using the temperature of minimum $p K$ value as a criterion of comparison.

Clarke and Glew [44] have suggested recently that eq (11), which expresses the variation of $p K$ with temperature, be expanded by the addition of an $A_{4} \ln T$ term and even $A_{5} T^{2}, A_{6} T^{3}$ terms on the right side. We find that the addition of an $A_{4} \ln T$ term in eq (11) leads, in some cases, to almost the same values of $t_{\min }$ and $p K_{\min }$ as those recorded in table 8. Thus, for acetic acid in deuterium oxide, $t_{\min }=32.6{ }^{\circ} \mathrm{C}, p K_{\min }=5.309$; for deuterioacetic acid in deuterium oxide, $t_{\min }=32.3, p K_{\min }=5.323$; for the second step in the dissociation of phosphoric acid in deuterium oxide, $t_{\min }=49.1{ }^{\circ} \mathrm{C}, p K_{\min }=7.743$. In these three cases, $t_{\min }$ lies within the temperature range over which $p K$ values were measured. But for the self-dissociation of water, where $t_{\min }$ is considerably above the highest temperature $\left(60^{\circ} \mathrm{C}\right)$ at which measurements were made, the addition of an $A_{4}$ $\ln T$ term to eq (11) leads to a value of $t_{\min }=327{ }^{\circ} \mathrm{C}$ and $p K_{\min }=10.982$. Moreover, a similar procedure with the self-dissociation constant of deuterium oxide leads to the conclusion that there is no minimum in the $p K$ versus $T$ curve. Hence, a valid treatment along these lines can be made only when experimental measurements at high temperatures are available.

The values of $\Delta p K_{\min }$ given in table 8 for acetic acid and deuterioacetic acid are almost identical. This not surprising; it would have been most unexpected to find any significant difference. However, the values of $\Delta p K_{\min }$ for acetic acid and for the second stage of dissociation of phosphoric acid differ by only 0.010 , despite the fact that for acetic acid $p K_{\min }$ (in $\left.\mathrm{H}_{2} \mathrm{O}\right)=4.756$ and for phosphoric acid $p K_{\min }\left(\right.$ in $\left.\mathrm{H}_{2} \mathrm{O}\right)$ is higher by 2.424 .

Although these results suggest that $\Delta p K$ at $t_{\min }$ may be independent of the strength of the acid, confirmation of this simple rule must await the availability of deuterium isotope effects for many more acids over a temperature range.

\section{Appendix}

\subsection{Dissociation Constants of Citric Acid at $25{ }^{\circ} \mathrm{C}$}

We have measured the emf at $25{ }^{\circ} \mathrm{C}$ of the cell

$$
\mathrm{Pt} ; \mathrm{D}_{2}, \mathrm{KD}_{2} \mathrm{Cit}(m), \mathrm{KCl}(m=0.01), \mathrm{AgCl} ; \mathrm{Ag}
$$

where Cit $=$ citrate, using cells with four different values of the citrate molality $(m)$. These values of $m$, together with the emf of the cell, are given in table 5, along with the values of $p\left(a_{\mathrm{D}} \gamma_{\mathrm{Cl}}\right)$ calculated with the aid of the standard potential of the silver-silver chloride electrode in deuterium oxide at $25^{\circ} \mathrm{C}$, namely $0.21266 \mathrm{~V}[23]$. 
For the dissociation processes

and

$$
\mathrm{D}_{3} \mathrm{Cit}=\mathrm{D}^{+}+\mathrm{D}_{2} \mathrm{Cit}^{-}
$$

$$
\mathrm{D}_{2} \mathrm{Cit}^{-}=\mathrm{D}^{+}+\mathrm{DCit}^{--}
$$

the following mass-law expressions can be written:

and

$$
K_{1}=a_{\mathrm{D}^{+}} \frac{m_{\mathrm{D}_{2} \mathrm{Cit}^{-}}}{m_{\mathrm{D}_{3} \mathrm{Cit}}} \frac{\gamma_{1}}{\gamma_{0}}
$$

$$
K_{2}=a_{\mathrm{D}^{+}} \frac{m_{\mathrm{DCit}^{--}}}{m_{\mathrm{D}_{2} \mathrm{Cit}^{-}}} \frac{\gamma_{2}}{\gamma_{1}}
$$

where the subscripts to $\gamma$ denote the charge of the citrate species. The condition for mass balance is $m=m_{\mathrm{D}_{3} \mathrm{Cit}}+m_{\mathrm{D}_{2} \mathrm{Cit}^{-}}+m_{\mathrm{DCit}^{--}}$, and the condition for electrical neutrality is

$$
m+m_{\mathrm{D}^{+}}=m_{\mathrm{D}_{2} \mathrm{Cit}^{-}}+2 m_{\mathrm{DCit}^{--}}+m_{\mathrm{OD}^{-}} .
$$

Hence, if $m_{\mathrm{D}^{+}}$and $m_{\mathrm{OD}^{-}}$are negligible compared with $m$,

Thus

$$
m_{\mathrm{D}_{3} \mathrm{Cit}}=m_{\mathrm{DCit}^{--}}
$$

$$
K_{1} K_{2}=\left(a_{\mathrm{D}^{+}}\right)^{2} \frac{\gamma_{2}}{\gamma_{0}}
$$

or

$$
\left(p K_{1}+p K_{2}\right) / 2=p a_{\mathrm{D}}-1 / 2 \log \frac{\gamma_{2}}{\gamma_{0}} .
$$

Making the reasonable assumption that $\gamma_{0} \approx 1$ and that $\log \gamma_{2}=4 \log \gamma_{\mathrm{Cl}^{-}}$, where $\log \gamma_{\mathrm{Cl}^{-}}$is given by eq (2), the convention proposed by Bates and Guggenheim [24], eq (18) can be written

$$
\left(p K_{1}+p K_{2}\right) / 2=p\left(a_{\mathrm{D}} \gamma_{\mathrm{Cl}}\right)-\log \gamma_{\mathrm{Cl}^{-}}
$$

Values of $\log \gamma_{\mathrm{Cl}^{-}}$, calculated with the aid of eq (2), are given in table 5 , together with values of $p\left(a_{\mathrm{D}} \gamma_{\mathrm{Cl}}\right)-\log$ $\gamma_{\mathrm{Cl}^{-}}$. If eq (19) were exact, the quantities on each side of the equation would be constant, independent of the total ionic strength. Table 5 shows that this is not strictly true, the value of $p\left(a_{\mathrm{D}} \gamma_{\mathrm{Cl}}\right)-\log \gamma_{\mathrm{Cl}^{-}}$increasing slowly as the concentration of potassium dideuteriocitrate in the cell solution decreases. This is undoubtedly due to minor imperfections in the assumptions we have made. These can be allowed for by rewriting eq (19) as follows:

$\left(p K_{1}+p K_{2}\right) / 2=p\left(a_{\mathrm{D}} \gamma_{\mathrm{Cl}}\right)-\log \gamma_{\mathrm{Cl}^{-}}+\beta I=\alpha+\beta I$.

Using the method of least squares, we find $\alpha=4.483$, $\beta=-0.0747 \mathrm{~kg} \mathrm{~mol}^{-1}$. Hence $\left(p K_{1}+p K_{2}\right) / 2=4.483$. As the corresponding quantity for ordinary water as solvent is 3.945 [45], it follows that $\Delta p K=0.538$.

Equation (18), however, is also not exact. A detailed examination of the problem requires a consideration of the effect of the third dissociation constant of citric acid [46, 47]. Let us consider the case of a tribasic acid at an initial concentration $m$, to which strong alkali is added in amount $x \mathrm{~m}$. Solution of the equations for electrical neutrality and mass balance yields the equation

$$
S K_{1} K_{2} K_{3}+R a_{\mathrm{D}^{+}} K_{1} K_{2}+Q a_{\mathrm{D}^{+}}^{2} K_{1}=P a_{\mathrm{D}^{+}}^{3}
$$

where, for solutions sufficiently acidic that $m_{\mathrm{OD}^{-}}$can be neglected, $P=\left(x m+m_{\mathrm{D}^{+}}\right) / \gamma_{0}, Q=\left[(1-x) m-m_{\mathrm{D}^{+}}\right] / \gamma_{1}$, $R=\left[(2-x) m-m_{\mathrm{D}^{+}}\right] / \gamma_{2}$, and $S=\left[(3-x) m-m_{\mathrm{D}^{+}}\right] / \gamma_{3}$, where again the subscript to $\gamma$ indicates the charge on the particular citrate species. The case with which we are now concerned is that in which sufficient alkali has been added to citric acid to complete the first stage of neutralization: $x=1$. Then

$$
\begin{aligned}
K_{1} K_{2}=\frac{m+m_{\mathrm{D}^{+}}}{m-m_{\mathrm{D}^{+}}} \frac{\gamma_{2}}{\gamma_{0}} a_{\mathrm{D}^{+}}^{2} & +\frac{m_{\mathrm{D}^{+}}}{m-m_{\mathrm{D}^{+}}} \frac{\gamma_{2}}{\gamma_{1}} K_{1} a_{\mathrm{D}^{+}} \\
& -\frac{2 m-m_{\mathrm{D}^{+}}}{m-m_{\mathrm{D}^{+}}} \frac{\gamma_{2}}{\gamma_{3}} \frac{K_{1} K_{2} K_{3}}{a_{\mathrm{D}^{+}}} .
\end{aligned}
$$

The second and third terms on the right of eq (22) are small compared with the first term; consequently, only approximate values of $K_{1}, K_{2}$, and $K_{3}$ are needed. These were obtained from the known values in water, together with $\Delta p K$ values read from figure 2 . The values used were $p K_{1}=3.67, p K_{2}=5.30$, and $p K_{3}=6.97$. Hence, $K_{1} K_{2}$ could be calculated, and the quantity $\left(p K_{1}+p K_{2}\right) / 2$ is given in the last row of table 5 . There is no systematic trend with change in concentration $m$, and we take the mean, 4.468 , as the best value of $\left(p K_{1}+p K_{2}\right) / 2$. Thus $\Delta p K=0.523$.

\subsection{First Dissociation Constant of Succinic Acid in Deuterium Oxide at $25{ }^{\circ} \mathrm{C}$}

We follow the method of Pinching and Bates [48]. Consider a solution of $\mathrm{D}_{2} \mathrm{~S}(3 m)+\mathrm{NaDS}(m)+\mathrm{NaCl}$ $\left(m^{\prime}\right)$, where $\mathrm{S}$ represents succinate. The first dissociation constant is given by the expression

$$
K_{1}=\frac{a_{\mathrm{D}^{+}} m_{\mathrm{DS}^{-}}-\gamma_{\mathrm{DS}^{-}}}{m_{\mathrm{D}_{2} \mathrm{~S}}} \gamma_{\mathrm{D}_{2} \mathrm{~S}}
$$

and the second dissociation constant by

$$
K_{2}=\frac{a_{\mathrm{D}^{+}} m_{\mathrm{S}^{--}} \gamma_{\mathrm{S}^{--}}}{m_{\mathrm{DS}^{-}} \gamma_{\mathrm{DS}^{-}}}
$$

From eq (24),

$$
m_{\mathrm{DS}^{-}}=\frac{a_{\mathrm{D}^{+}}}{K_{2}} \cdot m_{\mathrm{S}^{--}} \cdot \frac{\gamma_{\mathrm{S}^{--}}}{\gamma_{\mathrm{DS}^{-}}} .
$$

By the condition of electrical neutrality,

$$
m+m_{\mathrm{D}^{+}}=m_{\mathrm{DS}^{-}}+2 m_{\mathrm{S}^{--}}
$$

and by the condition of mass balance,

$$
m_{\mathrm{D}_{2 \mathrm{~S}}}+m_{\mathrm{DS}^{-}}+m_{\mathrm{S}^{--}}=4 m .
$$


From (26) and (27) it follows that

$$
m_{\mathrm{D}_{2} \mathrm{~S}}=3 m-m_{\mathrm{D}^{+}}+m_{\mathrm{S}^{--}}
$$

and from (25) and (26),

$$
m_{\mathrm{S}^{--}}\left(2+\frac{a_{\mathrm{D}^{+}}}{K_{2}} \cdot \frac{\gamma_{\mathrm{S}^{--}}}{\gamma_{\mathrm{DS}^{-}}}\right)=m+m_{\mathrm{D}^{+}} .
$$

For a solution of $\left(0.03689 m \mathrm{D}_{2} \mathrm{~S}+0.01230 \mathrm{~m} \mathrm{NaDS}\right.$ $+0.08609 \mathrm{~m} \mathrm{NaCl}$ ) in deuterium oxide at $25{ }^{\circ} \mathrm{C}$ (ref. 32 , table 1 , solution No. $4 \mathrm{a}$ ), it has been found that $p\left(a_{\mathrm{D}} \gamma_{\mathrm{Cl}}\right)=4.253$ and, by the Bates-Guggenheim convention [24], $-\log \gamma_{\mathrm{Cl}^{-}}=0.114$; hence, $p a_{\mathrm{D}}=4.139$. Assuming that $\log \gamma_{\mathrm{D}^{+}}=\log \gamma_{\mathrm{Cl}^{-}}$, we have $-\log m_{\mathrm{D}^{+}}$ $=4.025, m_{\mathrm{D}^{+}}=9.44 \times 10^{-5}$. The value of $p K_{2}$ is taken to be 6.209 (see the next section of the appendix). It is further assumed that $\log \left(\gamma_{\mathrm{S}^{--}} / \gamma_{\mathrm{DS}^{-}}\right)$in eq (25) is equal to $3 \log \gamma_{\mathrm{Cl}^{-}}$; it thus has the value -0.342 . Then by eq $(29), m_{\mathrm{S}^{--}}=0.00023$ and, by eq $(28), m_{\mathrm{D}_{2} \mathrm{~S}}=0.03703$, and, finally, by eq (27), $m_{\mathrm{DS}^{-}}=0.1193$. Substitution of these values in eq (23), along with the approximation $\log \left(\gamma_{\mathrm{DS}^{-}} / \gamma_{\mathrm{D}_{2} \mathrm{~S}}\right)=\log \gamma_{\mathrm{Cl}^{-}}=-0.114$, gives $p K_{1}=4.745$.

It is appropriate now to examine the assumptions we have made about the activity coefficient terms. Following the procedure of Pinching and Bates [48] for succinic acid in aqueous solution, we can write

where

$$
-\log m_{\mathrm{D}+}=p\left(a_{\mathrm{D}} \gamma_{\mathrm{Cl}}\right)+2 \log \gamma
$$

$$
-\log \gamma=\frac{A I^{1 / 2}}{1+7 B I^{1 / 2}}
$$

and $A$ and $B$ are the appropriate Debye-Hückel constants for deuterium oxide solutions $(A=0.5413$ $\mathrm{kg}^{1 / 2} \mathrm{~mol}^{-1 / 2}, B=0.3467 \times 10^{\beta} \mathrm{kg}^{1 / 2} \mathrm{~mol}^{-1 / 2} \mathrm{~cm}^{-1}$ at $25^{\circ} \mathrm{C}$ ). Substitution of these values in eq (31) for the solution considered above, with $I=0.09839$, gives $-\log \gamma=0.097, m_{\mathrm{D}+}=8.73 \times 10^{-5}$. If it is assumed with Pinching and Bates that the activity coefficients in eqs (23) and (25) can be calculated in the same way, we find $m_{\mathrm{S}--}=0.00021, \quad m_{\mathrm{D}_{2} \mathrm{~S}}=0.03701, \quad m_{\mathrm{DS}-}$ $=0.01197$, and $p K_{1}=4.743$.

Applying the first approach to a solution containing $0.03689 m \mathrm{D}_{2} \mathrm{~S}+0.01230 m \mathrm{NaDS}+0.01500 m \mathrm{NaCl}$ (see ref. 32 , table 1 , solution No. 4b) for which $I$ $=0.02730$, we find $p K_{1}=4.751$. Since we now have $p K_{1}=4.751$ at $I=0.02730$ and $p K_{1}=4.745$ at $I=0.09839$, the value of $p K_{1}$ at infinite dilution must be close to 4.753 . In ordinary water, $p K_{1}=4.207$ and, therefore, $\Delta p K=0.546$.

\subsection{Second Dissociation Constant of Succinic Acid in Deuterium Oxide at $25{ }^{\circ} \mathrm{C}$}

The calculation follows the method of Pinching and Bates [49]. Consider a solution of $\mathrm{NaDS}(m)+\mathrm{Na}_{2} \mathrm{~S}$ $(m)+\mathrm{NaCl}\left(m^{\prime}\right)$. From eq $(23)$

$$
m_{\mathrm{DS}^{-}}=\frac{K_{1}}{a_{\mathrm{D}+}} \cdot m_{\mathrm{D}_{2} \mathrm{~S}} \cdot \frac{\gamma_{\mathrm{D}_{2} \mathrm{~S}}}{\gamma_{\mathrm{DS}-}}
$$

By the condition of electrical neutrality,

$$
3 m+m_{\mathrm{D}+}=m_{\mathrm{DS}-}+2 m_{\mathrm{S}--}
$$

and by the condition of mass balance,

$$
m_{\mathrm{D}_{2} \mathrm{~S}}+m_{\mathrm{DS}-}+m_{\mathrm{S}--}=2 m .
$$

From eq (33) and (34), it follows that

$$
m_{\mathrm{DS}-}=m-m_{\mathrm{D}+}-2 m_{\mathrm{D}_{2 \mathrm{~S}}} .
$$

Combining eq (35) with eq (32) gives

$$
m_{\mathrm{D}_{2} \mathrm{~S}}\left(2+\frac{K_{1}}{a_{\mathrm{D}+}} \cdot \frac{\gamma_{\mathrm{D}_{2} \mathrm{~S}}}{\gamma_{\mathrm{DS}}}\right)=m-m_{\mathrm{D}+} .
$$

For a solution of $0.02007 \mathrm{~m} \mathrm{NaDS}+0.02007 \mathrm{~m}$ $\mathrm{Na}_{2} \mathrm{~S}+0.02007 m \mathrm{NaCl}$ in deuterium oxide at $25{ }^{\circ} \mathrm{C}$ (ref. 32, table 1, solution No. 6), $p\left(a_{\mathrm{D}} \gamma_{\mathrm{Cl}}\right)$ has been found to be 6.043 , and, again by the Bates-Guggenheim convention [24], $-\log \gamma_{\mathrm{Cl}-}=0.114, p a_{\mathrm{D}}=5.929$. If $\log \gamma_{\mathrm{D}+}$ is again taken equal to $\log \gamma_{\mathrm{Cl}}$, we have $-\log m_{\mathrm{D}+}=5.815, m_{\mathrm{D}+}=1.53 \times 10^{-6}$, and the deuterium ion correction is negligible. Putting $p K_{1}$ $=4.753$ (see appendix 5.2 above), eq (36) gives $m_{\mathrm{D}_{2} \mathrm{~S}}$ $=0.00093$ and, by eq (35), $m_{\mathrm{DS}_{-}}=0.01821$. Finally, by eq (34), $m_{\mathrm{S}--}=0.02100$ and, hence, by eq (24), $p K_{2}=6.205$. Pinching and Bates used eq (31) to express all the activity coefficients and, if we follow this procedure, we find $p K_{2}=6.171$. This is probably the better value, especially if a comparison with the $p K_{2}$ value in ordinary water $\left(5.638\right.$ at $\left.25{ }^{\circ} \mathrm{C}\right)$ is to be made; hence, $\Delta p K=0.533$.

\section{References}

[1] Urey, H. C., Brickwedde, F. G., and Murphy, G. M., Phys. Rev. 39, 864 (1932).

[2] Lewis, G. N., and Schutz, P. W., J. Amer. Chem. Soc. 56, 1913 (1934).

[3] Korman, S., and La Mer, V. K., J. Amer. Chem. Soc. 58, 1396 (1936).

[4] La Mer, V. K., and Chittum, J. P., J. Amer. Chem. Soc. 58, 1642 (1936).

[5] Rule, C. K., and La Mer, V. K., J. Amer. Chem. Soc. 60, 1974 (1938).

[6] Martin, D. C., and Butler, J. A. V., J. Chem. Soc. (London), 1366 (1939).

[7] Bell, R. P., The proton in chemistry, ch. 11 (Cornell University Press, Ithaca, N.Y., 1959).

[8] Bunton, C. A., and Shiner, V. J., J. Amer. Chem. Soc. 83, 42 (1961).

[9] Curry, J., and Hugus, Z. Z., J. Amer. Chem. Soc. 66, 653 (1944).

[10] Ballinger, P., and Long, F. A., J. Amer. Chem. Soc. 81, 2347 (1959).

[11] McDougall, A. O., and Long, F. A., J. Amer. Chem. Soc. 84, 429 (1962).

[12] Glasoe, P. K., J. Phys. Chem. 69, 4416 (1965).

[13] Bell, R. P., and Kuhn, A. T., Trans. Faraday Soc. 59, 1789 (1963).

[14] Dahlgren, G., and Long, F. A., J. Amer. Chem. Soc. 82, 1303 (1960).

[15] Glasoe, P. K., and Hutchison, J. R., J. Phys. Chem. 68, 1562 (1964).

[16] Glasoe, P. K., and Eberson, L., J. Phys. Chem. 68, 1560 (1964). 
[17] Sager, E. E., Robinson, R. A., and Bates, R. G., J. Res. NBS 68A (Phys. and Chem.), No. 3, 305 (1964).

[18] Robinson, R. A., J. Res. NBS 68A (Phys. and Chem.), No. 2, 159 (1964).

[19] Paabo, M., and Bates, R. G., Anal. Chem. 41, 283 (1969).

[20] Biggs, A. I., and Robinson, R. A., J. Chem. Soc. (London), 388 (1961).

[21] Högfeldt, E., and Bigeleisen, J., J. Amer. Chem. Soc. 82, 15 (1960).

[22] Gary, R., Bates, R. G., and Robinson, R. A., J. Phys. Chem. 69, 2750 (1965).

[23] Gary, R., Bates, R. G., and Robinson, R. A., J. Phys. Chem. 68, 1186 (1964).

[24] Bates, R. G., and Guggenheim, E. A., Pure Appl. Chem. 1, $163(1960)$.

[25] Harned, H. S., and Ehlers, R. W., J. Amer. Chem. Soc. 55, 652 (1933).

[26] Paabo, M., Bates, R. G., and Robinson, R. A., J. Phys. Chem 70, 540 (1966).

[27] Paäbo, M., Bates, R. G., and Robinson, R. A., J. Phys. Chem. 70, 2073 (1966).

[28] Bates, R. G., and Acree, S. F., J. Res. NBS 30, 129 (1943).

[29] Gary, R., Bates, R. G., and Robinson, R. A., J. Phys. Chem. 68, 3806 (1964).

[30] Harned, H. S., and Robinson, R. A., Trans. Faraday Soc. 36, 973 (1940).

[31] Covington, A. K., Robinson, R. A., and Bates, R. G., J. Phys. Chem. 70, 3820 (1966).

[32] Covington, A. K., Paabo, M., Robinson, R. A., and Bates, R. G., Anal. Chem. 40, 700 (1968).
[33] Harned, H. S., and Scholes, S. R., Jr., J. Amer. Chem. Soc. 63, 1706 (1941).

[34] Paabo, M., and Bates, R. G., J. Phys. Chem. (in press).

[35] Manov, G. G., DeLollis, N. J., and Acree, S. F., J. Res. NBS 33, 287 (1944).

[36] Bates, R. G., J. Res. NBS 47, 127 (1951).

[37] Robinson, R. A., Davis, M. M., Paabo, M., and Bower, V. E., J. Res. NBS 64A (Phys. and Chem.), No. 4, 347 (1960).

[38] Robinson, R. A., J. Chem. Eng. Data 14, 247 (1969).

[39] Lietzke, M. H., and Stoughton, R. W., J. Phys. Chem. 67, 652 (1963).

[40] Klotz, I. M., Singleterry, C. R., Theses, University of Chicago, 1940.

[41] Wehry, E. L., and Rogers, L. B., J. Amer. Chem. Soc. 88, 351 (1966).

[42] Pentz, L., and Thornton, E. R., J. Amer. Chem. Soc. 89, 6931 (1967)

[43] Harned, H. S., and Embree, N. D., J. Amer. Chem. Soc. 56, 1050 (1934).

[44] Clarke, E. C. W., and Glew, D. N., Trans. Faraday Soc. 62, 539 (1966).

[45] Bates, R. G., and Pinching, G. D., J. Amer. Chem. Soc. 71, 1274 (1949).

[46] Bates, R. G., J. Amer. Chem. Soc. 70, 1579 (1948).

[47] Robinson, R. A., and Stokes, R. H., Electrolyte solutions, p. 347, revised edition (Butterworths, London, 1968).

[48] Pinching, G. D., and Bates, R. G., J. Res. NBS 45, 444 (1950).

[49] Pinching, G. D., and Bates, R. G., J. Res. NBS 45, 322 (1950).

(Paper 73A3-553) 